\title{
CASE STUDY OF ENERGY CONSERVATION IN INDUSTRY BY APPLICATION OF LEAN TOOLS
}

\author{
N.Sujith Prasanna \\ Department of Mechanical Engineering \\ Amrita University, Coimbatore, Tamil Nadu, India
}

\author{
Dr.J.Nagesh Kumar \\ Director \\ Centre for Energy Environment and Productivity, \\ Chennai, Tamil Nadu, India
}

\begin{abstract}
Energy cost is significant in many of the manufacturing activities. The efficiency of energy use is quiet low as there are substantial visible and hidden losses. Visible losses can be easily identified and corrective action can be taken. However hidden and indirect losses form a sizeable portion of the losses. Identifying these losses is not easy and requires an integrated approach which includes thorough study of process, operations and their interactions with energy use. Industries across sectors have implemented lean management principles which target various wastes occurring in the plant. This paper discusses case studies which highlight the exploitation of lean tools as a means for unearthing hidden energy saving potential that often go unnoticed. In addition to the energy savings which results in improved profits and competitiveness, the approach also aids the industry to pursue a path of sustainable manufacturing.
\end{abstract}

Keywords - Lean manufacturing, Energy efficiency, sustainable manufacturing, Lean tools

\section{INTRODUCTION}

Manufacturers continuously face an increasingly competitive environment, where they are looking for opportunities to reduce the production costs without any negative effect to their productivity. Towards this objective more and more companies are focusing on eliminating waste to ensure customer satisfaction and maintain their profit growth. In recent years, many companies have established a fundamental goal to minimize the environmental impact while maintaining high quality and service for all business processes and products. There are also growing concerns worldwide about global warming and climate change due to the increasing use of fossil fuels fostered by rapid industrial growth. Responsible and sustainable manufacturing involving optimal use of resources is gaining ground which enhances the public image, increases market share and importantly decreases the cost of manufacturing.

Among the various inputs that contribute to manufacturing costs such as raw materials, labor, overheads, maintenance and energy, the one that is easily amenable for cost reduction is the energy cost. In India the industrial sector alone consumes more than $50 \%$ of the total energy consumption in the country. It has been found through different studies that there is a potential to improve the energy efficiency of industrial processes by $10-15 \%$ through a process of continual improvement. As most manufacturers are starting to realize, the quest to become green takes them right back to the lean manufacturing approach. Toyota's official formulation of lean management targets seven wastes of the modern workplace and designs its business strategies to fight them. These wastes include overproduction, transportation, waiting, inventory, motion, over processing and defects. Lean principles involve a systematic approach to identifying and eliminating waste through continuous improvement. This is one of the key ways to enhance environmental performance. It has been proven in many types of industries and different areas of manufacturing that lean implementation results in highly efficient production systems, and one of the several benefits is the significant environmental and energy gains. Without explicit consideration of energy wastes lean may overlook significant opportunities to improve performance and reduce costs.

Green Manufacturing is part of a continuous improvement strategy helping manufacturers to improve their productivity, profitability and competitiveness. The benefits of Green Manufacturing include reduced scrap and rework, reduced hazardous wastes, improved environmental performance, prevention of compliance and liability costs, reduced quantity of raw materials, resource and energy required to produce a product.

\section{OBJECTIVE}

The objective of this study is to highlight the contribution of lean implementation in energy saving to achieve a better environmental performance of production systems. This case study focuses on the analysis of the impact of selected lean tools on energy consumption in an industry. An application of the methodology in an LPG bottling plant is introduced. Based on the seven types of waste commonly used by lean practitioners, the opportunities for waste reduction and their expected impacts are identified. The Specific Energy Consumption i.e. energy consumption per tonne of LPG bottled before and after lean implementation has been 


\section{International Journal of Engineering Applied Sciences and Technology, 2021 \\ Vol. 5, Issue 12, ISSN No. 2455-2143, Pages 107-111 \\ Published Online April 2021 in IJEAST (http://www.ijeast.com)}

compared to show the use of selected lean tools and their impact on productivity and energy consumption.

\section{PROCESS DESCRIPTION}

The basic plant operation consists of receipt and storage of bulk LPG followed by filling and dispatching the same in cylinders of various sizes. The bulk LPG is received through LPG tankers by road. The plant has also has acquired additional land for the provision of Railway siding in future. The LPG is stored in mounded LPG bullets, dispatched through LPG Bulk tankers and LPG domestic \& Industrial cylinders. The total storage capacity is $1000 \mathrm{MT}$ of LPG. The types of cylinders filled are $14.2 \mathrm{~kg} / 19 \mathrm{~kg} / 5 \mathrm{~kg} / 35 \mathrm{~kg} / 47.5 \mathrm{~kg}$. The packed cylinders are delivered in a truck with a capacity of 342 cylinders and 504 cylinders to the market.

The bulk LPG is unloaded through reciprocating type unloading compressors by employing the pressure differential method. Here, LPG vapor is introduced in to the tank lorry and the vessel pressure is increased. As a result of the pressure difference between the lorry vessel and the bullets, LPG gets transferred to the bullet by a suitable pipeline arrangement. The same is illustrated in the following figure.

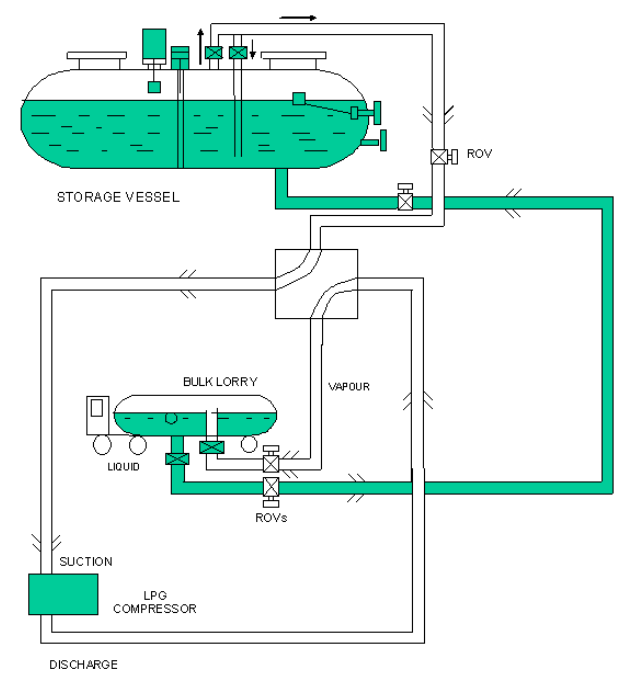

Further, LPG stored in the storage vessels is then pumped to the filling facility by means of centrifugal type LPG pumps. The filling facility consists of the electronic carousal with filling machines and other electro-pneumatic type post-filling quality check equipment. The following flow chart depicts the various operations carried out in the plant.

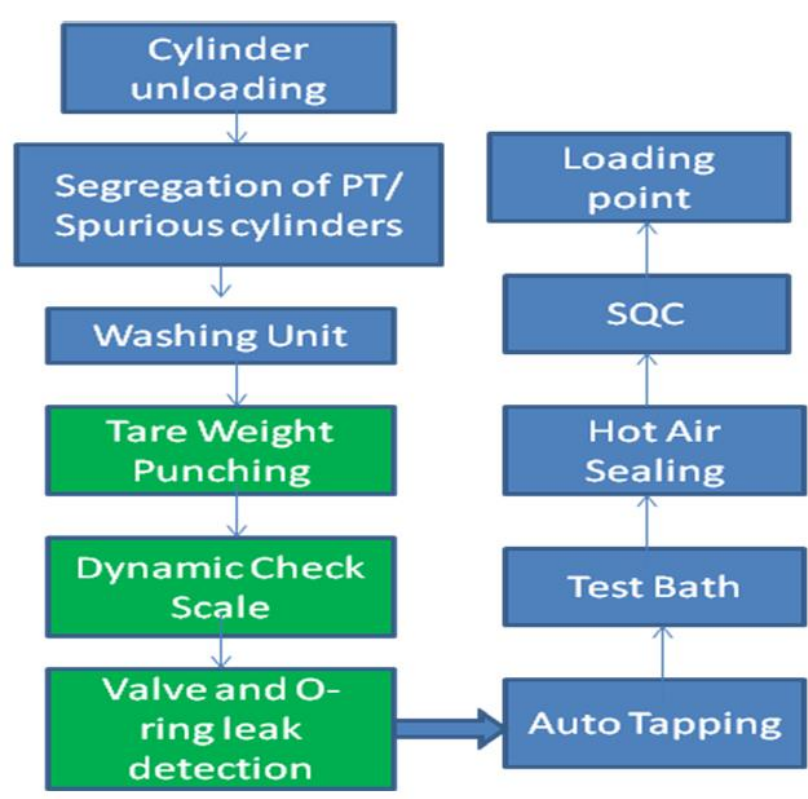

As illustrated in the flow chart, the cylinders are unloaded from the lorry on to the conveyors and the cylinders are sent to the carousal after segregation and washing. After filling at the carousal, the cylinder weight is verified at the check scale and weight is corrected if required. Further, the cylinder valve, oring and valve threads are checked for leakage at in-line electronic detectors. After this, the cylinder is capped and sent to Test bath for detection of body leaks. Once these checks are through, the cylinder is sealed and sent for loading on empty trucks. The statutory pressure testing of LPG cylinders is also carried out in the plant. First re-testing is required to be done after 10 years and subsequent re-testing after every 5 years interval.

\section{SPECIFIC ENERGy CONSUMPTION : The PERFORMANCE INDICATOR}

The plant receives its electrical energy from the local distribution company. The contract demand of the plant is 500 $\mathrm{kVA}$. Since it is a high tension consumer i.e. receiving power at $11 \mathrm{kV}$, the plant has to pay both demand charges and energy charges. The energy charges is based on kVAh. The annual energy consumption from Apr-19 to Mar-20 was 10,86,682 $\mathrm{kVAh}$. Based on the twelve months production and energy consumption, Specific Energy Consumption (SEC) has been worked out as kVAh/Metric Tonne. 


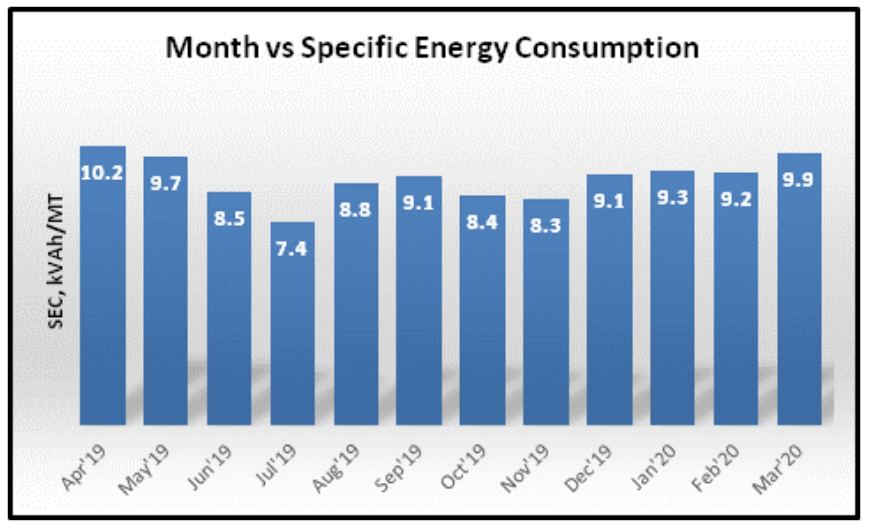

The SEC is found to vary between $10.3 \mathrm{kVAh} / \mathrm{MT}$ and 7.4 $\mathrm{kVAh} / \mathrm{MT}$ though the production remains more or less the same. With the best performance achieved being 7.4 $\mathrm{kVAh} / \mathrm{MT}$ in July'19, this can be the benchmark against which improvements can be targeted.

\section{APPLICATION OF LEAN TOOLS FOR ENERGY MANAGEMENT}

According to EPA (2007), "substantial energy savings typically ride the coattails of lean. By eliminating manufacturing wastes such as unnecessary processing and transportation, business also reduce the energy needed to power equipment, lighting, and cooling." Without explicit consideration of energy wastes, however, Lean may overlook significant opportunities to improve performance and reduce costs.

Case studies from the LPG Bottling Plant are discussed in the following paragraphs which substantiate the complementary nature of lean and energy efficiency.

\section{A. Value stream mapping for arresting compressed air leakages}

Value stream mapping offers a fresh way to evaluate processes, providing a system to create a flowchart that includes all the steps, activities, material flow and communication in a process. These processes can range from administrative processes to transforming raw materials into finished products. Each step is analyzed to find what adds value to a process and what does not. Non-value adding steps are eliminated. Many steps will be found to be unambiguously create value. Many other steps will be found to create no value but to be unavoidable with current technologies and production systems. In the audit of compressed air used in the plant the non value added areas were found to be use of pressure more than what was required and leakages.

During audit period, the audit team performed the leakage study of compressed air circuit. Leakage test was performed during non-production hours and the leakage points were mainly observed in joints and hose connects. Compressed air leakages points were identified and rectification measures were carried out to arrest the leakages. The trials revealed $21 \%$ leakage reduction in the system amounting to nearly 22,000 $\mathrm{kVAh}$ per year. Arresting the leakages resulted in an annual saving of $\$ 2,200$ per year.

The screw compressor in use had a 'Load - Unload' type of capacity control. The compressor was loading at 5.5 bar and unloading at 6.9 bar. A survey of compressed air use indicated that the maximum pressure required was 5 bar. Operating at excess pressure leads to higher energy consumption. The unloading pressure setting was reduced to 6 bar. This resulted in $7 \%$ energy saving amounting to $24,000 \mathrm{kVAh} /$ year. The monetary savings was $\$ 2,400$.

Yet another non value adding operation was the unloading of the compressors for about 4 hours/day. During unloading the compressor draws nearly $40 \%$ of the 'load' power without delivering any useful output. This is due to the constant quantity of the air supplied by the compressor and the varying demand at the user end. Providing a variable frequency drive will match the compressor output to the demand by varying the speed. This will eliminate unloading of the compressor and save unloading power. With an investment of $\$ 18,000$ the payback period works out to less than one year.

\section{B. Minimizing corrections and Rework}

Parts or units that do not meet the customer specification increases non-value added time. Defects always require some degree of additional attention, whether they are tracked, scrapped, reworked, or repaired. And these options may result in more waste in transportation, inventory, over-processing etc. Defects impact time, money, resources and customer satisfaction. Examples of Defects within a manufacturing environment include lack of proper documentation or standards, large variances in inventory, poor design and related design documentation changes and an overall lack of proper quality control throughout the process workflow.

The filled cylinders are sealed in a four-head sealing machine using electrical heaters. Due to the fluctuations in atmospheric temperature and inadequate response of the heaters to the thermostatic control about $15 \%$ defective sealing was observed in the line. Down the line these are again sealed using a portable sealing machine. The sealing machines use hot compressed air. The air is continuously passing throughout the day resulting in huge electrical energy losses. The main sealing machine was augmented with more electrical heaters as a result of which a constant temperature of $160^{\circ} \mathrm{C}$ was maintained. By this simple modification ' $100 \%$ right the first time' was achieved thus eliminating the need for portable 


\section{International Journal of Engineering Applied Sciences and Technology, 2021 \\ Vol. 5, Issue 12, ISSN No. 2455-2143, Pages 107-111 \\ Published Online April 2021 in IJEAST (http://www.ijeast.com)}

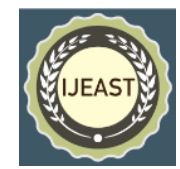

sealing machine. The savings in energy was 26,400 $\mathrm{kVAh} /$ year with an investment of $\$ 2000$.

\section{Over-processing: Eliminating the drying operation after cylinder washing}

Over-processing refers to doing more work, adding more components, or having more steps in a product or service than what is required by the customer. Over-processing as one of the seven wastes is caused by having unclear standards and specifications, many operators will try to do the best job possible and will not always be aware of what truly adds value to the product or even the end use. The most common issue is to do with design. Often designers specify tough requirements when in reality significantly less expensive methods could be employed by simplifying the operations.

The cylinders returned to the plant for filling are initially washed with water spray and subsequently is dried with a blower in a chamber. It was observed that by the time cylinder reaches the drier it is almost in 95\% dry state. The blower in the drying chamber was switched off and observations were made for an eight hour shift. It was noted that the blower did not add any value and the drying itself was an issue of overprocessing. The elimination of blower led to a saving of $12,000 \mathrm{kVAh} /$ annum without any investment.

\section{Reducing the cycle time}

Cycle Time is the amount of time a team spends actually working on producing an item, up until the product is ready for shipment. It is the time it takes to complete one task. This includes time spent producing the item and the wait between active work times.

LPG is pumped from the storage at a pressure of about 15-17 $\mathrm{kg} / \mathrm{cm} 2$. The pump is powered by a $75 \mathrm{~kW}$ motor with VFD. The filling rate of carousal 1 is 47 seconds/cylinder and that of carousal 2 is 45 seconds/cylinder. The pump is operated at $48.8 \mathrm{~Hz}$. The pump draws $50 \mathrm{~kW}$. It is suggested to increase the flow rate of the pump by increasing the frequency to 50 $\mathrm{HZ}$ and simultaneously increasing the speed of carousal 1 to deliver a cylinder in 45 seconds. A trial was conducted for the same. It resulted in an increase in production of 50 cylinders per hour. The pump was drawing $53 \mathrm{~kW}$ at $50 \mathrm{~Hz}$ and when operated with VFD in bypass mode it was drawing $50 \mathrm{~kW}$. Hence for no additional power, production is increased by $1.4 \%$.

\section{CONCLUSION}

Energy is a vital input to most production processes and value streams. By thinking explicitly about unnecessary energy use as another "Lean waste", organizations can significantly reduce costs and enhance competitiveness, while also achieving environmental performance goals. Energy efficiency study integrated with applications of lean principles conducted in this plant enabled it to reduce the energy consumption by $243,027 \mathrm{kVAh} / \mathrm{annum}$. This corresponds to Greenhouse Gas emissions reduction of 207 Tonnes of $\mathrm{CO}_{2}$ equivalent. The case studies demonstrate that implementing lean principles can result in significant energy reduction, and different lean tools can help in energy savings in different types of operations.

\section{REFERANCE}

[1] Graves R. , Konopka J.M, (1995), R.J. Milne Literature review of material flow control mechanisms Production Planning and Control, 6 (5) pp. 395-403

[2] Rother M., Shook J., (1999) "Learning to See: Value Stream Mapping to Add Value and Eliminate Muda the Lean Enterprise Institute" Inc., Brookline, MA.

[3] Liker J.K., (2004) The Toyota Way McGraw-Hill, New York

[4] Fawaz A., Abdulmalek, Jayant Rajgopal (2007), Analyzing the benefits of lean manufacturing and value stream mapping via simulation: A process sector case study Int. J. Production Economics, 107 pp. 223-236

[5] McDonald T., Van Aken E.M., Rentes A.F., (2002), Utilizing simulation to enhance value stream mapping: a manufacturing, case application International Journal of Logistics, Research and Applications, 5 (2) , pp. 213-232

[6] Rahani A.R., Muhammad al-Ashraf, (2012), Production Flow Analysis through Value Stream Mapping: A Lean Manufacturing Process Case Study Procedia Engineering, 41 pp. 1727-1734

[7] Monden Y., (1983), Toyota Production System Industrial Engineering and Management Press, Norcross, GA

[8] Jovanovic, V., Stevanov, B., Šešlija, D., Dudić, S., Tešić, Z., (2014), Energy efficiency optimization of air supply system in a water bottle manufacturing system, Journal of Cleaner Production, 85 pp. 306-317

[9] Milenković, I., (2014). Compressed air quality as a function of sustainable production, University of Novi Sad (PhD dissertation),

[10] Bhase P. and Lathkar M., (2015) "Energy conservation using VFD," International Conference on Energy Systems and Applications, Pune, , pp. 531-536.doi: 10.1109/ICESA.2015.7503406.

[11] Nancy Diaz-Elsayed, Annabel Jondral, Sebastian Greinacher, David Dornfeld, Gisela Lanza (2013) Assessment of lean and green strategies by simulation of manufacturing systems in discrete production environments CIRP Annals - Manufacturing Technology, 62 pp. 475-478. 
International Journal of Engineering Applied Sciences and Technology, 2021

Vol. 5, Issue 12, ISSN No. 2455-2143, Pages 107-111

Published Online April 2021 in IJEAST (http://www.ijeast.com)

[12] 26 July 2017 Guide to Good Industry Practices LPG Cylinder Filling, , World LPG Association, www.wlpga.org

[13] Citación: Gogula, V., Wan, H., \& Kuriger, G. (2011). Impact of lean tools on energy consumption. 